\title{
Biblioterapia na produção científica stricto sensu no Brasil
}

\author{
Bibliotherapy in the stricto sensu production of Brazil
}

\author{
Cristiano Moreira \\ Doutorando em Gestão e Organização do conhecimento \\ Universidade Federal de Minas Gerais \\ cristianomoreirasilva@hotmail.com \\ Raíssa Yuri Hamanaka \\ Doutoranda em Ciência da Informação \\ Universidade Estadual de Londrina \\ raissa0201@gmail.com
}

\section{Resumo}

Percebe-se que qualquer área do conhecimento, desde a sua gênese, norteia-se com base em paradigmas moldados pelas transformações sociais. Diante deste cenário, a profissão do bibliotecário vem sofrendo também inúmeras transformações oriundas das necessidades que envolvem seus usuários. A Biblioteconomia pode ser entendida como um campo científico que se preocupa em dar acesso a documentos, sendo caracterizada pelo enfoque material (das coleções de documentos), enfoque organizacional (relacionado a infraestrutura física e administrativa da biblioteca), enfoque intelectual (tratamento informacional dado aos documentos para que possam ser recuperados) e o enfoque do usuário. Neste sentido, surge como uma nova possibilidade de atuação a biblioterapia que consiste na adoção da leitura no tratamento de pacientes com algum tipo de transtorno psíquico ou psicológico. Por ser um ramo de atividade do bibliotecário ainda pouco explorado, pretende-se responder à seguinte questão de pesquisa: como a biblioterapia tem sido abordada na produção científica stricto sensu no Brasil? A pesquisa é caracterizada como qualitativa, com objetivos exploratório e descritivo e avaliou as teses e dissertações disponíveis nas bibliotecas digitais de teses e dissertações da Capes e do Ibict. Com a análise dos resultados, foi possível concluir que a biblioterapia tem sido pouco explorada na Ciência da Informação, o que demanda um esforço conjunto de pesquisadores e instituições de ensino para consolidar o estudo desta disciplina na perspectiva do bibliotecário.

\section{Palavras-chave}

Biblioterapia. Ciência da Informação. Biblioteconomia. Competências do bibliotecário.

\begin{abstract}
It is noticed that any area of knowledge, since its genesis, is guided by paradigms shaped by social transformations. In view of this scenario, the librarian's profession has also undergone numerous transformations arising from the needs that involve its users. Library Science can be understood as a scientific field that is concerned with giving access to documents, being characterized by the material focus (of the collections of documents), organizational focus (related to the physical and administrative infrastructure of the library), intellectual focus (informational treatment given to documents so that they can be recovered) and the focus of the user. In this sense, bibliotherapy appears as a new possibility of action which consists in the adoption of reading in the treatment of patients with some type of psychological disorder. As it is a field of activity of the librarian still little explored, we intend to answer the following research question: how is bibliotherapy being study in the stricto sensu production of Brazil? The research is characterized as qualitative, with exploratory and descriptive objec-
\end{abstract}


tives and evaluated the theses and dissertations available in the digital libraries of theses and dissertations of Capes and Ibict. With the analysis of the results, it was possible to conclude that bibliotherapy has been little explored in Information Science, which requires a joint effort by researchers and educational institutions to consolidate the study of this discipline from the perspective of the librarian.

\section{Keywords}

Bibliotherapy. Information Science. Library Science. Librarian skills.

\section{INTRODUÇÃO}

Na contemporaneidade é possível observar o crescimento de possibilidades de atuação para o profissional da informação, possivelmente devido ao novo paradigma vivenciado pela sociedade contemporânea, no qual a informação se tornou o principal insumo. Neste sentido, os profissionais da informação vêm aumentando o escopo de atuação (LAURINDO et al, 2016). Todavia, mesmo com essa amplitude de perspectivas, muitos ainda associam o bibliotecário à realização de procedimento de guarda, processamento e recuperação de informação (SANTA'ANNA; CALMON; CAMPOS, 2017).

Entre as diversas possibilidades de atuação do bibliotecário está a biblioterapia, que apesar de não ser vastamente conhecida não é uma disciplina nova (RIORDAN; WILSON, 1989). Segundo Riordan e Wilson (1989), a biblioterapia pode ter surgindo com as bibliotecas, pois, segundo eles, há muito os livros têm sido utilizados como conselheiros para os seus leitores, que encontram neles uma fonte de inspiração ou possibilidade de resposta a conflitos pessoais.

O termo biblioterapia é constituindo por duas palavras de origem grega - biblion $(\beta \iota \beta \lambda i o)=$ livro e therapeia $(\theta \varepsilon \rho \alpha \pi \varepsilon i \alpha)=$ terapia - que significam a adoção de livros e correlatos como instrumentos complementares ao tratamento de alguma enfermidade. A biblioterapia pode ser entendida como a utilização da literatura para promover a recuperação do paciente e sua reinclusão na sociedade (VALENCIA; MAGALHÃES, 2015).

Nesse sentido, nesta pesquisa se buscou responder à questão: como a biblioterapia tem sido abordada na produção científica stricto sensu no Brasil? Para responder a esta pergunta, teve-se o objetivo geral de descrever as abordagens de biblioterapia encontradas na produção científica stricto sensu no Brasil, por meio de pesquisa bibliográfica realizada na biblioteca digital de teses e dissertações da Coordenação de Aperfeiçoamento de Pessoal de Nível Superior (BDTD) da (Capes) e do Instituto Brasileiro de Informação em Ciência e Tecnologia (Ibict).

A pesquisa buscou mapear os conhecimentos norteadores ao profissional que atua ou pretende atuar no contexto da biblioterapia, apontando as principais competências do bibliotecário neste subcampo científico.

\section{REFERENCIAL TEÓRICO}

Neste referencial teórico é abordado o papel do bibliotecário na sociedade da informação, as novas competências necessárias ao bibliotecário em diversos domínios de atuação profissional, as características da biblioterapia e o entendimento da mesma no contexto internacional. 
A Biblioteconomia pode ser vista como uma das profissões mais antigas da humanidade, considerando-se a preservação da memória documental mundial (GARCIA, 2005). Arquivos, bibliotecas e museus se guiam pela premissa de manter, preservar e disseminar os acervos que representam o patrimônio histórico e cultural da sociedade na qual se situam. Embora este seja um princípio norteador básico, há características e objetivos específicos que diferenciam essas unidades informacionais (MARCONDES, 2016).

$\mathrm{Na}$ contemporaneidade o termo biblioteca não representa apenas uma coleção de livros, periódicos, mapas e objetos audiovisuais físicos, é possível vislumbrar a transição entre o mundo físico e o digital, que exige que a biblioteca se torne híbrida na tentativa de mediar a organização da informação física e digital. Não se trata apenas de conjuntos de documentos impressos, mas sim, de grandes volumes de dados não-estruturados produzidos em grande volume e velocidade no meio digital (MIRANDA; OLIVEIRA; SUAIDEN, 2008).

$O$ exponente crescimento informacional em larga escala e o avança das tecnologias da informação gerou profundas transformações não apenas na sociedade, mas também no contexto organizacional das bibliotecas. A dinamização da busca e recuperação informacionais impacta diretamente as necessidades dos usuários da informação e, consequentemente, as atribuições necessárias ao desempenho da função do bibliotecário. O papel do bibliotecário vem sendo influenciado pela multiplicidade de formatos de documentos, pela velocidade no acesso, e pelo grande volume de dados sendo gerado a cada segundo (GARCEZ; RADOS, 2002; VILLA BARAJAS; ALFONSO SÁNCHEZ, 2005).

O perfil de um profissional de uma área do conhecimento pode ser entendido como o conjunto de conhecimentos técnicos e habilidades específicas que um indivíduo deve possuir para exercer determinada profissão, isto é, como o conjunto de competências necessárias para o exercício da função profissional (MUELLER, 1989).

Na contemporaneidade, a adoção de inovações tecnológicas demanda um novo perfil de bibliotecário, o que exige constante atualização e realização de cursos de capacitação, bem como o desenvolvimento de habilidades que envolvam procedimentos de localização, seleção e acesso às informações pertinentes aos usuários informacionais (CAREGNATO, 2000). O Quadro 1 sintetiza algumas áreas de atuação do bibliotecário contemporâneo.

Quadro 1 - Áreas de atuação dos bibliotecários

\begin{tabular}{|c|l|l|}
\hline Função & \multicolumn{1}{|c|}{ Descrição } & \multicolumn{1}{|c|}{ Fonte } \\
\hline Preservação & $\begin{array}{l}\text { Responsável pela organização em um sentido } \\
\text { amplo (acervo em si e as infraestruturas do } \\
\text { espaço), de todo o conhecimento gerado pela } \\
\text { humanidade nas bibliotecas e outras institui- } \\
\text { ções, tornando possível o acesso a este conhe- } \\
\text { cimento. }\end{array}$ & $\begin{array}{l}\text { (MUELER, 1989); } \\
\text { (CARVALHO; MOTTA; FER- } \\
\text { NANDES, 2005) }\end{array}$ \\
\hline Educação & $\begin{array}{l}\text { Possui como atribuição auxiliar no acesso, por } \\
\text { meio do suporte a educação formal, garantindo } \\
\text { o uso correto pelos os usuários. }\end{array}$ & (MUELLER, 1989) \\
\hline Suporte ao estudo \\
e à pesquisa & $\begin{array}{l}\text { Possui a incumbência de possibilitar o munici- } \\
\text { amento de fontes e itens de informações aos } \\
\text { interessados. }\end{array}$ & (MUELLER, 1989) \\
\hline Planejamento & $\begin{array}{l}\text { O profissional é responsável pelo planejamento } \\
\text { e administração de recursos informacionais. }\end{array}$ & (MUELLER, 1989) \\
\hline Pesquisa & $\begin{array}{l}\text { Disponibilizar e manter meios que incentivem } \\
\text { as atividades relacionadas à pesquisa. }\end{array}$ & (MUELLER, 1989) \\
\hline
\end{tabular}




\begin{tabular}{|c|l|l|}
\hline $\begin{array}{c}\text { Organização e re- } \\
\text { presentação da } \\
\text { informação em } \\
\text { ambiente digital }\end{array}$ & $\begin{array}{l}\text { Possibilidade de atuação com arquitetura da } \\
\text { informação, análise de dados e tecnologia da } \\
\text { informação, Search Engine Optimization, gerên- } \\
\text { cia de projetos e da informação, inteligência } \\
\text { competitiva, análise de mídias sociais e desen- } \\
\text { volvimento de sistemas. }\end{array}$ & $\begin{array}{l}\text { (PALETTA; } \\
\text { SÁNCHEZ; } \\
\text { GONZÁLEZ, 2021) }\end{array}$ \\
\hline $\begin{array}{c}\text { Contexto do Big } \\
\text { Data e web semân- } \\
\text { tica }\end{array}$ & $\begin{array}{l}\text { Participar na estruturação e organização de } \\
\text { dados, identificar e tratar fontes de informação } \\
\text { confiáveis e identificar as necessidades dos } \\
\text { usuários. }\end{array}$ & $\begin{array}{l}\text { (CONEGLIAN; GONÇALVEZ; } \\
\text { SANTAREM SEGUNDO, } \\
\text { REM CONEGLIAN; SANTA- } \\
\text { REGUNDO; SAN- } \\
\text { TA'ANA, 2017; ARAÚJO } \\
\text { JÚNIO; SOUZA, 2016) }\end{array}$ \\
\hline $\begin{array}{c}\text { Contexto de trans- } \\
\text { formação digital }\end{array}$ & $\begin{array}{l}\text { Desenvolvimento de competências em infor- } \\
\text { mação para atuação em ambiente digital, hu- } \\
\text { manidades digitais. }\end{array}$ & $\begin{array}{l}\text { (HAMANAKA; BENIN; PALE- } \\
\text { TTA, 2021; HAMANAKA; } \\
\text { MADKUR; CONTANI, 2021) }\end{array}$ \\
\hline
\end{tabular}

Fonte: elaborado pelos autores (2021)

A diretriz curricular aplicada ao curso de Biblioteconomia (CNE/CES 492/2001) elenca habilidades gerais e específicas desejáveis ao perfil profissional do bibliotecário, conforme aponta o Quadro 2.

Quadro 2 - Habilidades gerais e específicas do bibliotecário conforme CNE/CES 492/2001

\begin{tabular}{|c|c|}
\hline Gerais & Específicas \\
\hline Criar e divulgar produtos. & \multirow{2}{*}{$\begin{array}{l}\text { Participar da elaboração e implementação de } \\
\text { recursos informacionais com um olhar crítico } \\
\text { e investigativo. }\end{array}$} \\
\hline Criar e implementar processos em instituições. & \\
\hline $\begin{array}{l}\text { Participar da concepção e implementação de proje- } \\
\text { tos pertentes à sua área de atuação. }\end{array}$ & \multirow{2}{*}{$\begin{array}{l}\text { Não se restringir à conservação de obras im- } \\
\text { pressas, atuando com qualquer tipo de fontes } \\
\text { informacionais. }\end{array}$} \\
\hline Aproveitar e empregar os meios disponíveis. & \\
\hline $\begin{array}{l}\text { Desenvolver novos mecanismos tecnológicos e ado- } \\
\text { tar os disponíveis na execução de sua atividade. }\end{array}$ & \multirow{2}{*}{$\begin{array}{l}\text { Absorver e gerir as fontes informacionais de } \\
\text { diversos tipos de suporte, aplicando o tecni- } \\
\text { cismo de sua área para organizar a posterior } \\
\text { difusão dessas informações. }\end{array}$} \\
\hline Identificar a carência de seu público-alvo. & \\
\hline $\begin{array}{l}\text { Incrementar as suas atividades de maneira indepen- } \\
\text { dente com o objetivo de atender às demandas que } \\
\text { são apresentadas, como emissão de laudos periciais. }\end{array}$ & \multirow{2}{*}{$\begin{array}{l}\text { Contribuir para a evolução de sua área por } \\
\text { meio de estudos sobre os produtos, proces- } \\
\text { samento e disponibilização desse conheci- } \\
\text { mento aos usuários. }\end{array}$} \\
\hline $\begin{array}{l}\text { Atender às necessidades sociais externas, no que } \\
\text { concerne à implementação de novas tecnologias. }\end{array}$ & \\
\hline
\end{tabular}

Fonte: elaborado com base em informações extraídas do CNE/CES 492 (2001)

Embora a biblioterapia tenha sido considerada uma disciplina da Biblioteconomia em 1914, ainda há discussões se a implementação da mesma deveria ser executada por bibliotecários (ALVES, 1982).

Segundo Pinto (2005), a biblioterapia é um campo propício para a atuação do bibliotecário, entretanto a aplicação da mesma demanda conhecimentos de outras áreas, pois a eficácia de sua implementação exige uma atuação em conjunto com psicólogos, terapeutas e afins. Neste sentido, a biblioterapia pode ser entendida como uma prática de incentivo à leitura para o tratamento de enfermidades, que envolve esforços de profissionais de diversas áreas (VIGUERA, 2017). 
A leitura empregada em uma função terapêutica fornece aos pacientes um apaziguamento, pois a prática de ler exerce no indivíduo o estímulo de suas emoções, ou seja, a literatura exerce uma função sedativa e curativa devido à capacidade de distrair, divertir, inspirar, apoiar e elevar a autoestima (CALDIN, 2001; PANELLA 2000; MCLAINE, 2017). A prática da biblioterapia consiste na indicação de uma obra que auxilie o paciente na resolução de seus problemas, sem absolvê-lo da situação e fornecendo condições para que reflita sobre suas angústias e busque possíveis soluções para as mesmas (ALVES, 1982).

Na década de 1930, a biblioterapia foi implementada no contexto brasileiro em hospitais destinados a tratar transtornos psiquiátricos, atualmente vem sendo utilizada para além de hospitais, haja vista que a leitura ou outros meios informacionais lúdicos, podem auxiliar no tratamento de problemas físicos e psíquicos do paciente (ALMEIDA et al., 2013; RIBEIRO, LÜCK, 2020).

É necessário ressaltar que a biblioterapia não pode ser entendida como o objeto informacional em si, ou seja, não pode ser entendida como o livro que atenuará o sofrimento do paciente. A prática da biblioterapia ocorre durante a leitura, no momento das reflexões que o paciente faz ao ler um livro e confrontá-lo com suas inquietações internas, possibilitando buscar respostas para os problemas que o afligem (SOUSA; CALDIN, 2018).

A biblioterapia pode ser caracterizada por seus componentes biblioterapêuticos: a catarse, o humor, a identificação, a introjeção, a projeção e a introspecção, que serão descritos no Quadro 3.

Quadro 3 - Definição dos componentes biblioterapêuticos

\begin{tabular}{|c|l|}
\hline Componentes & \multicolumn{1}{|c|}{ Descrição } \\
\hline A catarse & $\begin{array}{l}\text { Faz uso da literatura como um instrumento de apoio na terapia, contribuindo para } \\
\text { a aquietação, equilíbrio e atenuações psíquicas. }\end{array}$ \\
\hline o humor & $\begin{array}{l}\text { É uma maneira de distanciar o indivíduo do sofrimento protegendo-o do padeci- } \\
\text { mento. }\end{array}$ \\
\hline Identificação & $\begin{array}{l}\text { Ocorre quando o leitor se identifica com algo no texto que o faça repensar sobre o } \\
\text { tema, contribuindo para a sua transformação e entendimento sobre o mundo. }\end{array}$ \\
\hline Introjeção & $\begin{array}{l}\text { Relaciona-se com o componente anterior (identificação), levando o leitor a realizar } \\
\text { reflexões internas, devido a estímulos externos, no caso, oriundos da obra que está } \\
\text { sendo utilizada. }\end{array}$ \\
\hline Projeção & $\begin{array}{l}\text { Facilita que o paciente consiga transmitir suas ideias, sentimentos, expectativas e } \\
\text { desejos. }\end{array}$ \\
\hline Introspeção & $\begin{array}{l}\text { Quando o acesso a determinados tipos de obras, dependendo da situação em que } \\
\text { o paciente se encontre, favorece um momento de reflexão. }\end{array}$ \\
\hline
\end{tabular}

Fonte: elaborado com base em Caldin (2001)

A biblioterapia pode ser utilizada no campo correcional com criminosos, na área médica a fim de fornecer entretenimento para os pacientes hospitalizados ou como um meio de orientar sobre os possíveis tratamentos para determinadas enfermidades, enquanto na psiquiatria é frequentemente adotada para tratar vícios ou algum tipo de transtorno psíquico e na educação para tratar algum problema social enfrentado, como o divórcio, falecimento entre outros (ALVES, 1982). 
A biblioterapia não é somente empregada como forma de tratamento de enfermidades, também pode ser indicada como medida preventiva a enfermidades. Ribeiro e Lück (2020) corroboram a afirmação anterior, ao avaliarem a adoção da biblioterapia durante o isolamento social imposto pela Covid-19 e, concluem que a biblioterapia foi eficiente na preservação da saúde mental do público analisado, no caso, pesquisadores, docentes e discentes.

No âmbito internacional, as pesquisas de Panella (2000), Mclaine (2017), Viguera (2017), Mcnicol (2017) e Merga (2020) trazem entendimento relevante sobre biblioterapia. Panella (2000) desenvolveu diretrizes para bibliotecas que atendam pacientes em hospitais ou idosos e deficientes físicos em instituições de longa permanência. A partir de um grupo de colaboradores de vários países e extensa revisão bibliográfica foram identificadas diretrizes necessárias à implementação da biblioterapia, como, a identificação dos usuários, a organização do acervo a ser disponibilizado, o arranjo das instalações físicas, a capacitação necessária aos funcionários, o orçamento disponível, a seleção do acervo, a definição de programas e serviços a serem oferecidos e o plano de divulgação dos resultados alcançados com a biblioterapia. Panella (2000) ressalta que a biblioteca deve realizar a correta disseminação seletiva de informações aos seus usuários, levando em consideração as deficiências dos mesmos.

Mclaine (2017) identificou a biblioterapia criativa, por meio do monitoramento dos facilitadores que não atuavam na área clínica e foram treinados para atuarem com pacientes em suas comunidades. A aplicação de questionários aos facilitadores constatou a necessidade de incluir mais práticas de biblioterapia nos treinamentos dos mesmos a fim de maximizar o bem-estar da comunidade.

Viguera (2017) avaliou as possíveis contribuições da Biblioteconomia para a biblioterapia. Por meio da adoção de metodologia exploratória a autora identificou que o bibliotecário por meio das habilidades inerentes a sua área de atuação, como a comunicação e uso das tecnologias, pode exercer um papel essencial na implementação da biblioterapia. Enquanto Mcnicol (2017) investigou como o uso de revistas em quadrinhos vem ocorrendo na biblioterapia, por meio de uma entrevista estruturada com onze estudantes universitários, conclui que a adoção da leitura de quadrinhos pela biblioterapia ainda não tem sido eficientemente implementada.

Um dos estudos que tratam a implementação da biblioterapia é o de Merga (2020), que avalia como a adoção desta prática em bibliotecas escolares pode contribuir para o bem-estar do estudante. A autora conclui que as bibliotecas podem atuar como ambientes seguros, promovendo a saúde mental dos estudantes e incentivando o hábito da leitura de maneira prazerosa. A partir do estabelecimento do panorama sobre a temática biblioterapia, a seção seguinte apresenta a metodologia da pesquisa na análise da produção brasileira sobre a temática presente nas bases de teses e dissertações da Capes e do Ibict.

\section{METODOLOGIA}

De acordo com Gil (1994) uma pesquisa pode ser caracteriza conforme sua abordagem, seus objetivos e as técnicas que utiliza. Esta pesquisa teve abordagem qualitativa, caracterizada pela realização de análises indutivas sobre os dados coletados (MARCONI; LAKATOS, 2010). Os objetivos foram exploratórios e descritivos, pois foi abordada uma temática ainda em construção no contexto brasileiro: a biblioterapia e a produção acadêmica sobre essa temática foi analisada sob a perspectiva da Ciência da Informação e da Biblioteconomia. 
As técnicas utilizadas foram a o mapeamento de ementas de disciplinas em cursos de graduação de Biblioteconomia e pesquisa bibliográfica, que serão descritas ao longo desta seção. Foi realizado um estudo bibliométrico para identificação e análise da produção científica brasileira indexada nas BDTDs da Capes e do Ibict sobre a temática.

Na primeira etapa desta pesquisa, foi realizada uma busca no site do e-Mec (Cadastro Nacional de Cursos e Instituições de Educação Superior Cadastro) por instituições de ensino públicas e privadas que ofertassem a graduação em Biblioteconomia oferecida na modalidade presencial ou à distância. Foram encontradas 65 instituições credenciadas, destas foram eliminadas as instituições com o status "não iniciado" ou "extinto", o que resultou na amostra de 50 instituições com graduação em Biblioteconomia. Das 50 instituições de ensino 27 eram públicas federais, 6 privadas com fins lucrativos, 11 privadas sem fins lucrativos e 6 públicas estaduais públicas.

Em seguida, por meio de pesquisa documental, foram pesquisadas as grades curriculares de Biblioteconomia das 50 instituições mapeadas (no período de novembro de 2020), mas só foram encontradas online 41 grades curriculares. Das 41 grades curriculares analisadas, buscou-se o termo "biblioterapia" no nome das disciplinas das grades, sendo encontradas apenas duas disciplinas de biblioterapia, uma em um curso de Biblioteconomia de instituição privada e uma em instituição pública. Este mapeamento foi realizado a fim de verificar o desenvolvimento da biblioterapia no contexto da Biblioteconomia. Na segunda etapa desta pesquisa foi realizada a busca bibliográfica sobre pesquisas acadêmicas que abordam a biblioterapia.

A pesquisa bibliográfica busca o entendimento sobre um determinando assunto, estruturando as argumentações e conhecimentos consolidados na literatura de forma a possibilitar análises e a formulação de novos conhecimentos e argumentos, além de permitir a validação de estudos anteriores e o reuso de seus argumentos. Neste sentido, este método pode ter vários objetivos, entre eles: possibilitar um melhor entendimento sobre determinado assunto e avaliar os principais métodos e técnicas utilizadas em determinadas práticas (PIZZANI et al., 2012).

Para a realização da pesquisa bibliográfica foram adotadas as etapas processuais sugeridas por Lima e Mioto (2007), que objetivam estruturar a busca bibliográfica de maneira lógica para que as informações coletadas permitam responder ao problema da pesquisa. A adoção destas etapas evita que a recuperação das informações seja feita de forma aleatória, além de justificar para os leitores os critérios adotados no estudo, explicitando por quais motivos algum outro estudo não foi contemplado na presente revisão bibliográfica. O Quadro 4 apresenta as etapas realizadas durante a revisão bibliográfica da pesquisa.

Quadro 4 - Etapas a adotadas na revisão bibliográfica

\begin{tabular}{|l|l|}
\hline \multicolumn{1}{|c|}{ Procedimento } & \multicolumn{1}{c|}{ Descrição } \\
\hline Parâmetro temático & $\begin{array}{l}\text { Para contemplar esta fase do estudo, foram estipulados dois metadados de } \\
\text { consulta (biblioterapia e biblioterapy), nos resumos e títulos dos estudos } \\
\text { analisados. }\end{array}$ \\
\hline Parâmetro linguístico & Serão analisados os estudos desenvolvidos no Brasil. \\
\hline Principais fontes & $\begin{array}{l}\text { Foram utilizadas as dissertações e teses, disponibilizadas na Biblioteca Digi- } \\
\text { tal de Teses e Dissertações (BDTD) da Capes e do lbict. }\end{array}$ \\
\hline $\begin{array}{l}\text { Parâmetro cronológico } \\
\text { de publicação }\end{array}$ & $\begin{array}{l}\text { Foram utilizadas as pesquisas disponíveis nestas plataformas até novembro } \\
\text { de 2020. }\end{array}$ \\
\hline
\end{tabular}

Fonte: elaborado pelos autores (2021) 
Por meio destas etapas foi possível recuperar 24 documentos disponíveis online na BDTD da Capes e do lbict, esse corpus documental será analisado na seção 4 de forma a caracterizar a implementação da biblioterapia por pesquisadores brasileiros.

\section{RESULTADOS E DISCUSSÕES}

Neste tópico, serão apresentados os principais resultados obtidos no desenvolvimento da pesquisa e a análise dos mesmos.

\subsection{Adoção da disciplina de biblioterapia nos cursos de Biblioteconomia}

Conforme aponta a literatura científica, a biblioterapia não pode ser considerada competência profissional apenas do bibliotecário, por isso, foi realizada uma avaliação das disciplinas oferecidas pelos cursos de graduação em Biblioteconomia brasileiros, com o intuito de verificar se a biblioterapia é uma disciplina vem sendo ofertada para a formação dos futuros bibliotecários. A Tabela 1 apresenta os currículos que foram encontrados com a oferta da disciplina de biblioterapia.

Tabela 1 - Avaliação da disponibilização da disciplina de biblioterapia

\begin{tabular}{l|c|c|c|c}
\hline \multicolumn{1}{c|}{ Instituição de Ensino } & Total de currículos & Não localizados & Analisados & Biblioterapia \\
\hline $\begin{array}{l}\text { Privada com fins lucrati- } \\
\text { vos }\end{array}$ & 6 & 4 & 2 & 0 \\
\hline $\begin{array}{l}\text { Pública estadual } \\
\text { Privada sem fins lucrati- } \\
\text { vos }\end{array}$ & 6 & 0 & 6 & 0 \\
\hline Pública federal & 11 & 4 & 7 & 1 \\
\hline \multicolumn{1}{c|}{ Total } & $\mathbf{5 0}$ & 1 & 26 & 1 \\
\hline
\end{tabular}

Fonte: dados da pesquisa (2021)

A partir da Tabela 1, percebe-se que dos 50 currículos teoricamente disponíveis dos cursos de Biblioteconomia de instituições públicas e privadas, apenas 41 foram efetivamente encontrados online, e destes, somente 2 currículos da graduação em Biblioteconomia apresentaram a disciplina biblioterapia explicitamente identificada no nome da disciplina, sendo um currículo da instituição privada Rede de Ensino Claretiano e um da instituição pública Universidade Federal de Santa Catarina. Pinheiro e Ramires (2020) corroboram este resultado ao identificarem apenas um currículo de biblioterapia em Biblioteconomia em uma instituição de ensino pública. É possível que os autores não tenham encontrado o segundo currículo, por terem realizado um recorte de instituições públicas ou, também é possível que na época de realização da pesquisa, a instituição privada com curso de Biblioteconomia e com currículo em biblioterapia, talvez ainda não estivesse credenciada no e-Mec.

Com base nos resultados, não é possível afirmar que os recém-formados em Biblioteconomia estão saindo para o mercado sem o conhecimento necessário sobre os conceitos e práticas relacionados a biblioterapia, pois existe a possibilidade deste conteúdo estar sendo ensinado em uma disciplina com outro nome, já que não há um padrão imposto pelo MEC para a adoção da nomenclatura de disciplinas pelas instituições. Conforme a lei no 10.861, de 14 de abril de 2004, que cria instrumentos para a avaliação do curso superior no contexto brasileiro, cada curso irá dispor de seu projeto pedagógico, tendo autonomia para criar o 
currículo e avaliar e definir os conhecimentos necessários para a formação do futuro profissional.

Mesmo existindo um desenho curricular, a Biblioteconomia ainda enfrenta algumas incompreensões de sua legitimidade social e simbólica, no que se refere ao entendimento de suas práticas de saber-fazer e fazer-saber (PINTO, 2005). Neste sentido, a não existência mínima da difusão das práticas de biblioterapia, na graduação, pode prejudicar a formação de bibliotecários que por desconhecimento, não terão condições de exercer esta especialidade, devido ao despreparo teórico e prático para atuar no tratamento de pacientes por meio do incentivo à leitura.

\subsection{Avaliação do uso da biblioterapia em teses e dissertações da BDTD da Capes e do Ibict}

Na segunda etapa da pesquisa, foram mapeadas e avaliadas teses e dissertações no contexto nacional que empregaram o uso da biblioterapia. A Tabela 2 descreve os resultados do mapeamento.

Tabela 2 - Dissertações e teses recuperadas na BDTD da Capes e do lbict

\begin{tabular}{c|c|c}
\hline Tipo & Capes & BDTD \\
\hline Dissertações & 21 & 15 \\
\hline Teses & 2 & 1 \\
\hline Total & 23 & 16 \\
\hline
\end{tabular}

Fonte: dados da pesquisa, 2020

Na BDTD da Capes e do Ibict foram recuperados ao todo 39 documentos, porém excluindo-se os repetidos restaram 27 teses e dissertações, destes 27 documentos apenas 24 estavam disponíveis online, portanto, o corpus de análise é composto por 24 teses e dissertações. Em seguida, os 24 documentos recuperados foram analisados sobre duas variáveis: o uso da biblioterapia e a identificação da área do conhecimento. É necessário ressaltar que 2 dos 24 documentos não utilizaram de fato a biblioterapia, apesar fazerem menção à técnica. O Quadro 5 relaciona caracteriza o uso da biblioterapia no corpus de análise.

Quadro 5 - Teses e dissertações do corpus documental que utilizaram a biblioterapia

\begin{tabular}{|c|c|c|c|}
\hline BDTD & Documento & $\begin{array}{l}\text { Área do conhe- } \\
\text { cimento }\end{array}$ & Aplicação da biblioterapia \\
\hline $\begin{array}{l}\text { Capes } \\
\text { e Ibict }\end{array}$ & $\begin{array}{l}\text { D01. PEREIRA, A. M. G. } \\
\text { S. Leitura para enfer- } \\
\text { mos: uma experiência } \\
\text { em um hospital psiqui- } \\
\text { átrico. } 1987 \text {. }\end{array}$ & $\begin{array}{l}\text { Ciência da In- } \\
\text { formação }\end{array}$ & $\begin{array}{l}\text { A pesquisa buscou entender qual o papel da } \\
\text { leitura para os enfermos. Um questionário foi } \\
\text { aplicado em uma amostra de } 20 \text { pacientes e } \\
\text { uma das conclusões foi que a biblioterapia foi } \\
\text { útil para o programa correcional. }\end{array}$ \\
\hline Capes & $\begin{array}{l}\text { D02. PEREIRA, M. M. G. } \\
\text { A biblioterapia em } \\
\text { instituições de defici- } \\
\text { entes visuais: um estu- } \\
\text { do de caso. } 1990 \text {. }\end{array}$ & $\begin{array}{l}\text { Ciência da In- } \\
\text { formação }\end{array}$ & $\begin{array}{l}\text { Avaliou a adoção da biblioterapia em deficien- } \\
\text { tes visuais da Paraíba, como metodologia fo- } \\
\text { ram aplicados dois questionários, um no início } \\
\text { do projeto e outro ao final. Concluiu-se que o } \\
\text { uso da biblioterapia contribuiu para a melho- } \\
\text { ria na motivação e aprendizagem dos avalia- } \\
\text { dos. }\end{array}$ \\
\hline
\end{tabular}




\begin{tabular}{|c|c|c|c|}
\hline Capes & $\begin{array}{l}\text { D03. VAZQUEZ, M. S. A. } \\
\text { F. Biblioterapia para } \\
\text { idosos: um estudo de } \\
\text { caso no Lar da Provi- } \\
\text { dencia Carneiro da } \\
\text { Cunha. } 1990 .\end{array}$ & $\begin{array}{l}\text { Ciência da In- } \\
\text { formação }\end{array}$ & $\begin{array}{l}\text { Estudo de caso aplicado em uma instituição } \\
\text { que cuida de idosos, sediada em João Pessoa. } \\
\text { Por meio de práticas intervencionistas, perce- } \\
\text { beu-se que o hábito da leitura reduziu a ansie- } \\
\text { dade e depressão dos envolvidos. }\end{array}$ \\
\hline Capes & $\begin{array}{l}{ }^{1} \text { FREITAS, A. J. P. Pro- } \\
\text { dução acadêmica do } \\
\text { curso de mestrado em } \\
\text { Biblioteconomia da } \\
\text { UFPB. 1993. }\end{array}$ & $\begin{array}{l}\text { Ciência da In- } \\
\text { formação }\end{array}$ & Indisponível online. \\
\hline Capes & $\begin{array}{l}\text { CRUZ, M. A. L. Bibliote- } \\
\text { rapia de desenvolvi- } \\
\text { mento pessoal: pro- } \\
\text { grama adolescente de } \\
\text { periferia. } 1995 .\end{array}$ & $\begin{array}{l}\text { Ciência da in- } \\
\text { formação }\end{array}$ & Indisponível online. \\
\hline $\begin{array}{l}\text { Capes } \\
\text { e lbict }\end{array}$ & $\begin{array}{l}\text { D04. SEITZ, E. M. Bibli- } \\
\text { oterapia: uma experi- } \\
\text { ência com pacientes } \\
\text { internados em clínica } \\
\text { médica. } 2000 .\end{array}$ & $\begin{array}{l}\text { Engenharia de } \\
\text { Produção }\end{array}$ & $\begin{array}{l}\text { Pesquisa realizado no Hospital Universitário da } \\
\text { Universidade Federal de Santa Catarina, bus- } \\
\text { cando avaliar a prática da biblioterapia, isto é, } \\
\text { buscando avaliar a introdução da literatura } \\
\text { neste contexto. Foram entrevistados } 47 \text { paci- } \\
\text { entes que indicaram a importância da literatu- } \\
\text { ra no cenário estudado. }\end{array}$ \\
\hline $\begin{array}{l}\text { Capes } \\
\text { e lbict }\end{array}$ & $\begin{array}{l}\text { D05. CALDIN, C. F. A } \\
\text { poética da voz e da } \\
\text { letra na literatura in- } \\
\text { fantil: leitura de alguns } \\
\text { projetos de contar e ler } \\
\text { para crianças. } 2001 .\end{array}$ & Literatura & $\begin{array}{l}\text { Estudou a prática de escutar e narrar textos } \\
\text { infantis, por meio da realização de leituras } \\
\text { críticas e reflexões sobre os assuntos aborda- } \\
\text { dos. }\end{array}$ \\
\hline Capes & $\begin{array}{l}\text { D06. HASSE, M. Biblio- } \\
\text { terapia como texto: } \\
\text { análise interpretativa } \\
\text { do processo bibliotera- } \\
\text { pêutico. } 2004 \text {. }\end{array}$ & $\begin{array}{c}\text { Comunicação e } \\
\text { Linguagens }\end{array}$ & $\begin{array}{l}\text { Analisou a biblioterapia por meio da técnica } \\
\text { interpretativa-dialógica, embasado na teoria } \\
\text { semiótica de Eco e Peirce. Foi realizado um } \\
\text { estudo de vários casos clínicos que fizeram uso } \\
\text { da biblioterapia e sobre os procedimentos } \\
\text { envolvidos nesta praática. }\end{array}$ \\
\hline $\begin{array}{l}\text { Capes } \\
\text { e lbict }\end{array}$ & $\begin{array}{l}\text { D07. SILVA, A. M. Ca- } \\
\text { racterísticas da produ- } \\
\text { ção documental sobre } \\
\text { biblioterapia no Brasil. } \\
2005 \text {. }\end{array}$ & Psicologia & $\begin{array}{l}\text { Pesquisa bibliográfica sobre a biblioterapia no } \\
\text { contexto brasileiro, por meio de análise de } \\
\text { dados, conclui que apesar da biblioterapia ser } \\
\text { pouco conhecida, conhecimento científico } \\
\text { está sendo produzido sobre a temática na } \\
\text { esfera acadêmica e profissional. }\end{array}$ \\
\hline Capes & $\begin{array}{l}\text { D8. ROSA, A. L. R. As } \\
\text { cartas de Ana Cristina } \\
\text { César: uma contribui- } \\
\text { ção para a bibliotera- } \\
\text { pia. } 2006 \text {. }\end{array}$ & Letras & $\begin{array}{l}\text { Utilizando as cartas da poeta Ana Cristina Cé- } \\
\text { sar, a pesquisadora identificou os efeitos tera- } \\
\text { pêuticos do uso deste gênero literário na bibli- } \\
\text { terapia. Por meio de estudo de caso, a autora } \\
\text { concluiu que a biblioterapia possui além do } \\
\text { efeito curativo o efeito preventivo. }\end{array}$ \\
\hline
\end{tabular}

\footnotetext{
${ }^{1}$ As referências indisponíveis online não compuseram o corpus de análise, pois não puderam ser consultadas e analisadas. Entretanto, compõem o mapeamento de teses e dissertações sobre biblioterapia e foram registradas nos resultados.
} 


\begin{tabular}{|c|c|c|c|}
\hline $\begin{array}{l}\text { Capes } \\
\text { e lbict }\end{array}$ & $\begin{array}{l}\text { D9. BACHERT, C. M. D. } \\
\text { Estratégias da bibliote- } \\
\text { rapia de desenvolvi- } \\
\text { mento aplicadas na } \\
\text { orientação de proble- } \\
\text { mas de disciplina. } \\
2006 \text {. }\end{array}$ & Psicologia & $\begin{array}{l}\text { Avaliação do programa de desenvolvimento } \\
\text { de habilidades sociais, direcionado para orien- } \\
\text { tar alunos que apresentam problemas discipli- } \\
\text { nares. Questionários foram aplicados a } 27 \\
\text { estudantes no período extracurricular em vá- } \\
\text { rios momentos da observação. Constatou-se } \\
\text { que o uso da biblioterapia promoveu a melho- } \\
\text { ra da autoestima dos envolvidos. }\end{array}$ \\
\hline $\begin{array}{l}\text { Capes } \\
\text { e lbict }\end{array}$ & $\begin{array}{l}\text { D10. MIRANDA, M. R. } \\
\text { P. F. Informação, leitu- } \\
\text { ra e inclusão educacio- } \\
\text { nal e social em biblio- } \\
\text { tecas braille de Campo } \\
\text { Grande/MS: um estudo } \\
\text { de caso. } 2006 \text {. }\end{array}$ & $\begin{array}{l}\text { Ciência da In- } \\
\text { formação }\end{array}$ & $\begin{array}{l}\text { Apesar de ter utilizado o termo "biblioterapia" } \\
\text { como indexador, não utilizou esta técnica. }\end{array}$ \\
\hline Ibict & $\begin{array}{l}\text { T01. CERIBELLI, C. A } \\
\text { mediação de leitura } \\
\text { como recurso de co- } \\
\text { municação com crian- } \\
\text { ças e adolescentes } \\
\text { hospitalizados: subsí- } \\
\text { dios para a humaniza- } \\
\text { ção do cuidado de En- } \\
\text { fermagem. } 2007 \text {. }\end{array}$ & Saúde Pública & $\begin{array}{l}\text { Realizou a avaliação de um projeto de incenti- } \\
\text { vo à leitura em crianças e adolescentes. Por } \\
\text { meio da observação de mediações de leitura e } \\
\text { da realização de entrevistas, foi possível con- } \\
\text { cluir que a biblioterapia facilita a comunicação } \\
\text { e as relações sociais durante o período de } \\
\text { internação. }\end{array}$ \\
\hline $\begin{array}{l}\text { Capes } \\
\text { e lbict }\end{array}$ & $\begin{array}{l}\text { T02. CALDIN, C. F. Lei- } \\
\text { tura e terapia. } 2009 .\end{array}$ & Literatura & $\begin{array}{l}\text { Realizando uma pesquisa bibliográfica, por } \\
\text { meio dos métodos fenomenológicos, a pesqui- } \\
\text { sadora identificou que as práticas literárias } \\
\text { presentes na biblioterapia possuem o efeito } \\
\text { terapêutico. }\end{array}$ \\
\hline Ibict & $\begin{array}{l}\text { D11. GUIMARÃES, F. } \\
\text { "Mas ele diz que me } \\
\text { ama": impacto da his- } \\
\text { tória de uma vítima na } \\
\text { vivência de violência } \\
\text { conjugal de outras } \\
\text { mulheres. } 2009 \text {. }\end{array}$ & Psicologia & $\begin{array}{l}\text { Avaliando a obra literária, "Mas ele diz que me } \\
\text { ama", o pesquisador buscou o impacto da } \\
\text { história da personagem desta obra na vida de } \\
\text { outras mulheres. Como método, foram aplica- } \\
\text { dos questionários em grupos focais. Esta es- } \\
\text { tratégia se mostrou eficiente no auxílio de } \\
\text { mulheres que sofrem com violência conjugal. }\end{array}$ \\
\hline Capes & $\begin{array}{l}\text { GIACOMONI, L. Media- } \\
\text { dores de leitura e bi- } \\
\text { blioterapia no contexto } \\
\text { hospitalar. } 2010 .\end{array}$ & Letras & Indisponível online. \\
\hline Capes & $\begin{array}{l}\text { D12. GREENHALGH, M. } \\
\text { G. G. A biblioterapia na } \\
\text { realidade bibliotecária } \\
\text { no Brasil. } 2013 \text {. }\end{array}$ & $\begin{array}{l}\text { Gestão da Infor- } \\
\text { mação }\end{array}$ & $\begin{array}{l}\text { Estudou o papel do bibliotecário brasileiro na } \\
\text { implementação da biblioterapia, aplicando } \\
\text { entrevistas e questionários. Os resultados } \\
\text { apontaram a importância do bibliotecário na } \\
\text { implementação desta prática, identificando a } \\
\text { escassez de cursos para prepara-lo na adoção } \\
\text { da biblioterapia. }\end{array}$ \\
\hline Capes & $\begin{array}{l}\text { T03. PAULA, D. Espiri- } \\
\text { tualidade terapêutica: } \\
\text { critérios da logoterapia } \\
\text { aplicados na lectio }\end{array}$ & Teologia & $\begin{array}{l}\text { Utilizou como panorama a identificação da } \\
\text { espiritualidade em um momento terapêutico, } \\
\text { ao avaliar a logoterapia na esfera psicotera- } \\
\text { peuta. O pesquisador identificou que a logote- }\end{array}$ \\
\hline
\end{tabular}




\begin{tabular}{|c|c|c|c|}
\hline & $\begin{array}{l}\text { divina para reabilitação } \\
\text { de adictos. } 2013 .\end{array}$ & & rapia adota elementos da biblioterapia. \\
\hline $\begin{array}{l}\text { Capes } \\
\text { e lbict }\end{array}$ & $\begin{array}{l}\text { D13. JESUS, A. S. Signi- } \\
\text { ficados sobre a doença } \\
\text { e a hospitalização na } \\
\text { infância contidos em } \\
\text { livros para criança. } \\
2014 \text {. }\end{array}$ & Educação & $\begin{array}{l}\text { Avaliou as narrativas que tratam sobre doença } \\
\text { e crianças hospitalizadas. Foram analisadas } 12 \\
\text { obras infantis, e segundo as análises as crian- } \\
\text { ças doentes apesar de enfrentarem problemas } \\
\text { psíquicos tem o papel dos amigos saudáveis } \\
\text { para a recuperação. }\end{array}$ \\
\hline $\begin{array}{l}\text { Capes } \\
\text { e lbict }\end{array}$ & $\begin{array}{l}\text { D14. GARCIA, I. H. Bi- } \\
\text { blioterapia: percepções } \\
\text { dos discentes dos cur- } \\
\text { sos de biblioteconomia } \\
\text { das universidades fe- } \\
\text { deral e estadual de } \\
\text { Santa Catarina. } 2014 \text {. }\end{array}$ & $\begin{array}{l}\text { Ciência da In- } \\
\text { formação }\end{array}$ & $\begin{array}{l}\text { Identificou as percepções de duas instituições } \\
\text { de ensino superior sobre a biblioterapia. Utili- } \\
\text { zando a análise de discurso, por meio de en- } \\
\text { trevistas e questionários, foi possível identifi- } \\
\text { car que os alunos compreendem a bibliotera- } \\
\text { pia como uma disciplina importante, apesar de } \\
\text { identifica-la como ainda um subcampo cientí- } \\
\text { fico ainda muito incipiente. }\end{array}$ \\
\hline $\begin{array}{l}\text { Capes } \\
\text { e lbict }\end{array}$ & $\begin{array}{l}\text { D15. TRASMONTANO, } \\
\text { P. S. Percepções acerca } \\
\text { da espiritualidade arti- } \\
\text { culada à biblioterapia } \\
\text { enquanto experiência } \\
\text { vivenciada no cuidado } \\
\text { integral aos pacientes } \\
\text { com HIV e Aids: uma } \\
\text { perspectiva fenomeno- } \\
\text { lógica. } 2015 \text {. }\end{array}$ & Enfermagem & $\begin{array}{l}\text { Estudou a percepção dos pacientes de HIV e } \\
\text { Aids sobre a espiritualidade, com base nas } \\
\text { práticas da biblioterapia. Realizou levanta- } \\
\text { mento de campo, fazendo uso da observação, } \\
\text { questionários e entrevistas. Conclui que as } \\
\text { práticas de biblioterapia aplicadas foram capa- } \\
\text { zes de promover o apoio emocional. }\end{array}$ \\
\hline $\begin{array}{l}\text { Capes } \\
\text { e lbict }\end{array}$ & $\begin{array}{l}\text { D16. SILVA, C. S. Biblio- } \\
\text { terapia no Brasil e na } \\
\text { Polônia: distâncias e } \\
\text { aproximações a partir } \\
\text { da literatura científica. } \\
2017 .\end{array}$ & $\begin{array}{l}\text { Gestão da Infor- } \\
\text { mação }\end{array}$ & $\begin{array}{l}\text { Identificou as características das práticas de } \\
\text { biblioterapia no Brasil e na Polônia, avaliando } \\
\text { pesquisas publicadas no período de } 2000 \text { a } \\
2015 \text {, que foram analisadas segundo o método } \\
\text { de análise de conteúdo. Conclui-se que há } \\
\text { práticas de biblioterapia sendo adotadas na } \\
\text { Polônia que podem auxiliar o desenvolvimento } \\
\text { desta no Brasil. }\end{array}$ \\
\hline $\begin{array}{l}\text { Capes } \\
\text { e lbict }\end{array}$ & $\begin{array}{l}\text { D17. CHAGAS, R. L. } \\
\text { Rede de bibliotecas em } \\
\text { ambientes de saúde } \\
\text { mental: um diálogo } \\
\text { interdisciplinar. } 2017 .\end{array}$ & $\begin{array}{l}\text { Gestão da Infor- } \\
\text { mação }\end{array}$ & $\begin{array}{l}\text { Apesar de ter utilizado o termo "biblioterapia" } \\
\text { como indexador, não utilizou esta técnica. }\end{array}$ \\
\hline Capes & $\begin{array}{l}\text { D18. SILVA, E. F. M. } \\
\text { Biblioterapia: a contri- } \\
\text { buição da literatura } \\
\text { infantil na construção } \\
\text { da autoestima da cri- } \\
\text { ança. } 2018 .\end{array}$ & $\begin{array}{l}\text { Desenvolvimento } \\
\text { e Sociedade }\end{array}$ & $\begin{array}{l}\text { Analisou como a adoção das práticas de bibio- } \\
\text { terapia podem influenciar no fortalecimento } \\
\text { da autoestima de crianças, e consequente- } \\
\text { mente nos relacionamentos sociais. A metodo- } \\
\text { logia utilizada foi a pesquisa-ação. }\end{array}$ \\
\hline Capes & $\begin{array}{l}\text { D19. SEIXAS, C. G. S. } \\
\text { Vagar sem pressa no } \\
\text { esconderijo da vida } \\
\text { alada: em busca da }\end{array}$ & Educação & $\begin{array}{l}\text { Avaliou as dimensões do conhecimento na } \\
\text { promoção da formação docente. Identificou } \\
\text { que encontros e práticas de arterapia tem } \\
\text { elevado potencial para o resgate da essência }\end{array}$ \\
\hline
\end{tabular}




\begin{tabular}{|c|c|c|c|}
\hline & $\begin{array}{l}\text { alma na educação. } \\
2018 .\end{array}$ & & na educação. \\
\hline Capes & $\begin{array}{l}\text { D20. WIEGAND, S. C. B. } \\
\text { Enfrentamento da do- } \\
\text { ença rara na infância: } \\
\text { uma reflexão bioética } \\
\text { sobre o luto. } 2018 \text {. }\end{array}$ & Bioética & $\begin{array}{l}\text { Avaliou o enfrentamento da doença na infân- } \\
\text { cia, com base na literatura que explora esta } \\
\text { temática, como resultado identificou a neces- } \\
\text { sidade de ter cuidado com este perfil de paci- } \\
\text { ente. }\end{array}$ \\
\hline Ibict & $\begin{array}{l}\text { D21. SILVA, T. M. C. } \\
\text { Biblioterapia no en- } \\
\text { frentamento do bul- } \\
\text { lying na infância. } 2020 .\end{array}$ & Saúde Coletiva & $\begin{array}{l}\text { Identificou a percepção sobre a prevenção do } \\
\text { bullying na educação infantil, por meio da } \\
\text { experiência de docentes. A metodologia utili- } \\
\text { zada foi a realização de entrevistas semiestru- } \\
\text { turadas, e da observação-participante, identi- } \\
\text { ficando-se que a biblioterapia é um importan- } \\
\text { te instrumento no combate ao bullying na } \\
\text { infância. }\end{array}$ \\
\hline
\end{tabular}

Fonte: dados da pesquisa (2021)

Conforme foi apurado a maior concentração dos estudos analisados foram de dissertações, havendo 24 dissertações ( 21 disponíveis online) e 3 teses (todas disponíveis online), o que caracterizou a amostra de 24 documentos, 21 dissertações e 3 teses e destes apenas 22 utilizaram ou se aprofundaram na temática de biblioterapia.

Como pode se verificar a biblioterapia está sendo utilizando em várias áreas do conhecimento, sendo possível identificar o desenvolvimento de estudos na área de: Saúde Coletiva, Bioética, Educação, Desenvolvimento e Sociedade, Enfermagem, Letras, Literatura, Saúde Pública, Psicologia, Ciência da Informação e Engenharia de Produção. Este fato corrobora com o discutido na literatura e é comprovado no estudo de Pinheiro e Ramires (2020), que concluíram que não existe uma única área do conhecimento responsável pela implementação da biblioterapia, sendo uma área multidisciplinar.

Entre as áreas do conhecimento identificadas a maior concentração de pesquisas é na Ciência da Informação (com dez trabalhos na amostra analisada), podendo indicar possíveis interesses de pesquisa na área, apesar de não existir um número significativo de disciplinas ofertadas no âmbito da graduação, conforme evidenciado no Quadro 1, esta temática tem sido mais explorada na modalidade stricto sensu.

Neste contexto, a bilblioterapia tem sido aplicada para inúmeros fins, como para o tratamento de pacientes hospitalizados e para diversos tratamentos psíquicos, aplicados a crianças, adolescentes, idosos, entre outros. Porém, a partir dos resultados em ambas as bases (BDTD da Capes e do lbict), verifica-se que na perspectiva dos programas stricto sensu a biblitoerapia ainda é pouca explorada, chegando a um total de apenas 27 trabalhos, que nas últimas décadas, se dedicaram ao estudo exploratório da biblioterapia, o que torna moroso a evolução e o aprimoramento desta disciplina.

A produtividade científica pequena no que concerne a utilização da biblioterapia também é presente na perspectiva de artigos acadêmicos, conforme é relatado no estudo Gadelha e Tanus (2019), ao realizaram levantamento bibliográfico sobre a biblioterapia em artigos científicos e constatarem a reduzida aplicação da disciplina, mais reduzida ainda no contexto da Ciência da Informação e Biblioteconomia.

Os resultados desta pesquisa apontam a necessidade de elaboração de novas pesquisas que explorem esta temática, com o objetivo de amadurecer o entendimento sobre o 
assunto e as práticas que envolvem esta possibilidade de atuação, a fim de que a biblioterapia se torne uma disciplina consolidada dentro do campo da Biblioteconomia e possa gradualmente evoluir do ponto de vista científico.

\section{CONSIDERAÇÕES FINAIS}

A profissão do bibliotecário há muito deixou de ser entendida como uma prática restrita a bibliotecas, haja vista que a evolução tecnológica impôs uma demanda de constante atualização profissional e das práticas que envolvem o desenvolvimento de suas atividades.

Nesse sentido, a biblioterapia vem se tornando uma das possíveis áreas de atuação do profissional, sendo necessário um amadurecimento e uma preparação humanística do bibliotecário para o atendimento desta nova demanda informacional, que por sua vez é abordada por diversos campos científicos.

A partir dos resultados obtidos nesta pesquisa, é necessário avaliar os motivos que levam a disciplina de biblioterapia não ser majoritariamente ofertada nos cursos de graduações oferecidos no contexto brasileiro. É necessário ponderar que a não atualização pelas instituições de ensino de seus projetos pedagógicos em seus sites pode ter impactado os resultados desta pesquisa. Além disso, as ofertas reduzidas da disciplina biblioterapia podem indicar que seu conteúdo deva ser buscado em cursos especializados por estudantes que queiram aprofundar os conhecimentos nessa vertente. A atualização dos currículos e das disciplinas ofertadas nos cursos de Biblioteconomia, se torna necessária não apenas em relação à biblioterapia, mas também em âmbitos mais amplos como a necessidade de desenvolvimento de habilidades tecnológicas para a atuação no atual contexto de transformação digital.

Foi possível identificar que a biblioterapia vem sendo aplicada por variadas áreas do conhecimento, como psicologia, medicina, letras e educação o que demonstra seu caráter multidisciplinar e demanda dos bibliotecários um amplo conhecimento, de modo a contribuir com as demais áreas do conhecimento no tratamento destes pacientes. Nesse sentido, é importante que se desenvolvam pesquisas futuras com o enfoque na prática da biblioterapia e buscando resultados capazes de melhorar a qualidade de vida da sociedade.

A limitação da pesquisa se deu em relação ao recorte da realidade brasileira e ao contexto reduzido da pesquisa bibliográfica, o que torna os dados não passíveis de generalização. Como pesquisa futura sugere-se investigar se a escassez da oferta da disciplina de biblioterapia também é presente em cursos oferecidos em outros países, avaliando quais possíveis variáveis influenciam a ocorrência deste fato. Também sugere-se avaliar se esta disciplina é oferecida em outros cursos como o de Psicologia, por exemplo, e se há influências dos tecnicismos da Biblioteconomia no conteúdo ofertado.

\section{Referências}

ALMEIDA, Edson Marques et al. Biblioterapia: o bibliotecário como agente integrador e socializador da informação. Múltiplos Olhares em Ciência da Informação, Belo Horizonte, v. 3, n. 2, 2013.

ALVES, Maria Helena Hees. A aplicação da Biblioterapia no processo de reintegração social. Revista Brasileira de Biblioteconomia e Documentação, v. 15, n. 1/2, p. 54-61, jan./jun. 1982. 
ARAÚJO JÚNIOR, Rogério Henrique; SOUZA, Renato Tarciso Barbosa. Estudo do ecossistema de Big Data para conciliação das demandas de acesso, por meio da representação e organização da informação. Ciência da Informação, Brasília, v. 45, n. 3, p. 187-198, set./dez. 2016.

BRASIL. Ministério de Educação e Cultura. Resolução CNE/CES 492/2001, de 03 de abril de 2001. Institui Diretrizes Curriculares Nacionais dos Cursos de Filosofia, História, Geografia, Serviço Social, Comunicação Social, Ciências Sociais, Letras, Biblioteconomia, Arquivologia e Museologia. Diário Oficial da União, Brasília, 09 de julho de 2001.

BRASIL. Lei no 10.861, de 14 de abril de 2004. Institui o Sistema Nacional de Avaliação da Educação Superior-SINAES e dá outras providências. Diário Oficial da União, n. 72, 2004.

CALDIN, Clarice Fortkamp. A leitura como função terapêutica: biblioterapia. Encontros Bibli: revista eletrônica de biblioteconomia e ciência da informação, Florianópolis, v. 6, n. 12, p. 32-44, 2001.

CAREGNATO, Sônia Elisa. O desenvolvimento de habilidades informacionais: o papel das bibliotecas universitárias no contexto da informação digital em rede. Revista de Biblioteconomia e Comunicação, Porto Alegra, v. 8, p. 47-55, jan./dez. 2000.

CARVALHO, Maria da Conceição; MOTTA, Rosemary Tofani; FERNANDES, Cleide Aaparecida. A preservação de acervos de bibliotecas e sua importância na atualidade: a ótica dos bibliotecários da UFMG. Informação \& Sociedade: estudos, João Pessoa, v. 15, n. 1, jan./jun. 2005.

CONEGLIAN, Caio Saraiva; GONÇALVEZ, Paula Regina Ventura Amorim; SANTARÉM SEGUNDO, José Eduardo. O Profissional da Informação na Era do Big Data. Encontros Bibli: revista eletrônica de biblioteconomia e ciência da informação, Florianópolis, v. 22, n. 50, p. 128-143, set./dez. 2017. ISSN 1518-2924. DOI: 10.5007/1518-2924.2017v22n50p128

CONEGLIAN, Caio Saraiva; SANTAREM SEGUNDO, José Eduardo; SANT'ANA, Ricardo César Gonçalves. Big Data: fatores potencialmente discriminatórios em análise de dados. Encontros Bibli: revista eletrônica de biblioteconomia e ciência da informação, Florianópolis, v. 23, n. 1, p. 62-86, jan./abr. 2017.

HAMANAKA, Raíssa Yuri; MADKUR, Federico Natalio; CONTANI, Miguel Luiz. Um ensaio sobre o papel do profissional da informação na era do Big Data. In: COLÓQUIO EM ORGANIZAÇÃO, ACESSO E APROPRIAÇÃO DA INFORMAÇÃO E DO CONHECIMENTO, 5., 2021, Londrina. Anais [...]. Londrina: Universidade Estadual de Londrina, 2021.

HAMANAKA, Raíssa Yuri; BENIN, Keli Rodrigues do Amaral; PALETTA, Francisco Carlos. Transformação digital: um ensaio sobre o Big Data, análise de dados e inteligência artificial. In: COLÓQUIO EM ORGANIZAÇÃO, ACESSO E APROPRIAÇÃO DA INFORMAÇÃO E DO CONHECIMENTO, 5., 2021, Londrina. Anais [...]. Londrina: Universidade Estadual de Londrina, 2021. 
GADELHA, Jessica da Silva; TANUS, Gabrielle Francinne de de Souza Carvalho. Biblioterapia: análise dos artigos indexados na Base de Dados em Ciência da Informação (BRAPCI). Ciência da Informação em Revista, Maceió, v. 6, n. 1, p. 159-176, jan./abr. 2019.

GARCEZ, Eliane Maria Stuart; RADOS, Gregório Jean Varvakis. Biblioteca híbrida: um novo enfoque no suporte à educação a distância. Ciência da Informação, Brasília, v. 31, n. 2, p. 4451, maio/ago. 2002.

GARCIA, Joana Coeli Ribeiro. Preservação das memórias: marca da Biblioteconomia. Informação \& Sociedade: estudos, João Pessoa, v. 15, n. 2, 2005.

GIL, Antônio Carlos. Métodos e técnicas de pesquisa social. 4. ed. São Paulo: Atlas, 1994.

LAURINDO, Kariane Regina et al. Empresas criadas por bibliotecários no Brasil: uma análise em relação ao perfil e ramos de atuação. Revista ACB, Florianópolis, v. 21, n. 3, p. 676-696, ago./nov. 2016.

LIMA, Telma Cristiane Sasso de; MIOTO, Regina Célia Tamaso. Procedimentos metodológicos na construção do conhecimento científico: a pesquisa bibliográfica. Revista Katálysis, Florianópolis, v. 10, n. SPE, p. 37-45, abr. 2007.

MARCONDES, Carlos Henrique. Interoperabilidade entre acervos digitais de arquivos, bibliotecas e museus: potencialidades das tecnologias de dados abertos interligados. Perspectivas em Ciência da Informação, Belo Horizonte, v. 21, n. 2, p. 61-83, abr./jun. 2016.

MARCONI, Marina de Andrade; LAKATOS, Eva Maria. Fundamentos de metodologia científica. 7. ed. São Paulo: Atlas, 2010.

MCLAINE, Susan. Looking Beyond Traditional Bibliotherapy: A New View. Journal of the Australian Library and Information Association, v. 66, n. 3, p. 306-307, 2017.

MCNICOL, Sarah. The potential of educational comics as a health information medium. Health Information \& Libraries Journal, v. 34, n. 1, p. 20-31, 2017.

MERGA, Margaret. How can school libraries support student wellbeing? Evidence and implications for further research. Journal of Library Administration, v. 60, n. 6, p. 660-673, 2020.

MIRANDA, Antonio; OLIVEIRA, Cecília Leite; SUAIDEN, Emir José. A biblioteca híbrida na estratégia da inclusão digital na Biblioteca Nacional de Brasília. Inclusão Social, Brasília, v. 3, n. 1, p. 17-23, out. 2007/mar.2008.

MUELLER, Suzana Pinheiro Machado. Perfil do bibliotecário, serviços e responsabilidades na área de informação e formação profissional. Revista de Biblioteconomia de Brasília, Brasília, v. 17, n. 1, p. 63-70, 1989.

PALETTA, Francisco Carlos; PASTOR-SÁNCHEZ, Juan Antonio; MOREIRO-GONZÁLEZ, José Antonio. Competências e habilidades digitais requeridas aos profissionais da informação nos 
anúncios brasileiros de emprego na web. Profesional de la información, v. 30, n. 1, 2021. DOI: https://doi.org/10.3145/epi.2021.ene.08

PANELLA, Nancy Mary. Guidelines for libraries serving hospital patients and the elderly and disabled in long-term care facilities. Hague: IFLA Headquarters, 2000.

PINHEIRO, Mariza Inês da Silva; RAMIRES, Daniela Duarte. Biblioterapia: das dissertações e teses aos cursos de Biblioteconomia no Brasil. Ciência da Informação em Revista, Maceió, v. 7, n. 1, p. 153-167, 2020.

PINTO, Virginia Bentes. A biblioterapia como campo de atuação para o bibliotecário. Transinformação, Campinas, v. 17, n. 1, jan./abr. 2005.

PIZZANI, Luciana et al. A arte da pesquisa bibliográfica na busca do conhecimento. RDBCI: Revista Digital de Biblioteconomia e Ciência da Informação, Campinas, v. 10, n. 2, p. 53-66, jul./dez. 2012.

RIBEIRO, Natasha Coutinho Revoredo; LÜCK, Esther Hermes. Biblioterapia em tempos de COVID-19. Revista Brasileira de Educação em Ciência da Informação, São Paulo, v. 7, n. especial, p. 24-53, 2020.

RIORDAN, Richard J.; WILSON, Linda S.. Bibliotherapy: does it work? Journal of Counseling \& Development, v. 67, n. 9, p. 506-508, 1989.

SANTA'ANNA, Jorge; CALMON, Maria Aparecida de Mesquita; CAMPOS, Suelen de Oliveira. A percepção do aluno iniciante e do aluno concluinte do Curso de Biblioteconomia de uma universidade a respeito do bibliotecário: enfoque na atuação profissional. Biblos, Rio Grande, v. 31, n. 2, p. 130-146, 2017.

SOUSA, Carla; CALDIN, Clarice Fortkamp. Biblioterapia e Hermenêutica: revisitando Gadamer e Ouaknin. Perspectivas em Ciência da Informação, Belo Horizonte, v. 23, n. 2, p. 174-188, abr./jun. 2018.

VALENCIA, Maria Cristina Palhares; MAGALHÃES, Michelle Cristina. Biblioterapia: síntese das modalidades terapêuticas utilizadas pelo profissional. Biblos, Rio Grande, v. 29, n. 1, 2015.

VIGUERA, Yenifer Castro. Bibliotherapy and selection of information sources: a field of activity for library and information science professionals. Bibliotecas: Análes de Investigación, v. 13, n. 1, p. 82-95, jan./jul. 2017.

VILLA BARAJAS, Herminia; ALFONSO SÁNCHEZ, Ileana R. Biblioteca híbrida: el bibliotecario en medio del tránsito de lo tradicional a lo moderno. Acimed, Ciudad de La Habana, v. 13, n. 2, p. 1-1, 2005. 